\title{
Enabling Thin and Flexible Solid-State Composite Electrolytes by Scalable Solution Process
}

Darren H.S. Tan, ${ }^{a}$ Ahbik Banerjee , ${ }^{a}$ Zhi Deng, ${ }^{a}$ Erik A. Wu,${ }^{a}$ Han Nguyen, ${ }^{a}$ Jean-Marie Doux, ${ }^{a}$ Xuefeng Wang, ${ }^{a}$ Ju-hsiang Cheng, ${ }^{a}$ Shyue Ping Ong, ${ }^{a, b}$ Ying. Shirley Meng, ${ }^{a, b^{*}}$ Zheng Chen ${ }^{a, b, c}{ }^{*}$

a Department of NanoEngineering, University of California San Diego, La Jolla, CA 92093

${ }^{\mathrm{b}}$ Sustainable Power \& Energy Center (SPEC), University of California San Diego, La Jolla, CA 92093

'Program of Chemical Engineering, University of California San Diego, La Jolla, CA 92093

*Correspondence to: shmeng@ucsd.edu; zhengchen@eng.ucsd.edu

This PDF file includes:

Supplementary text

Figs. S1 to S8

Tables S1 \& S2

Other supplementary materials for this manuscript include the following:

Supporting Information for Publication - Movies $1 \& 2$ 

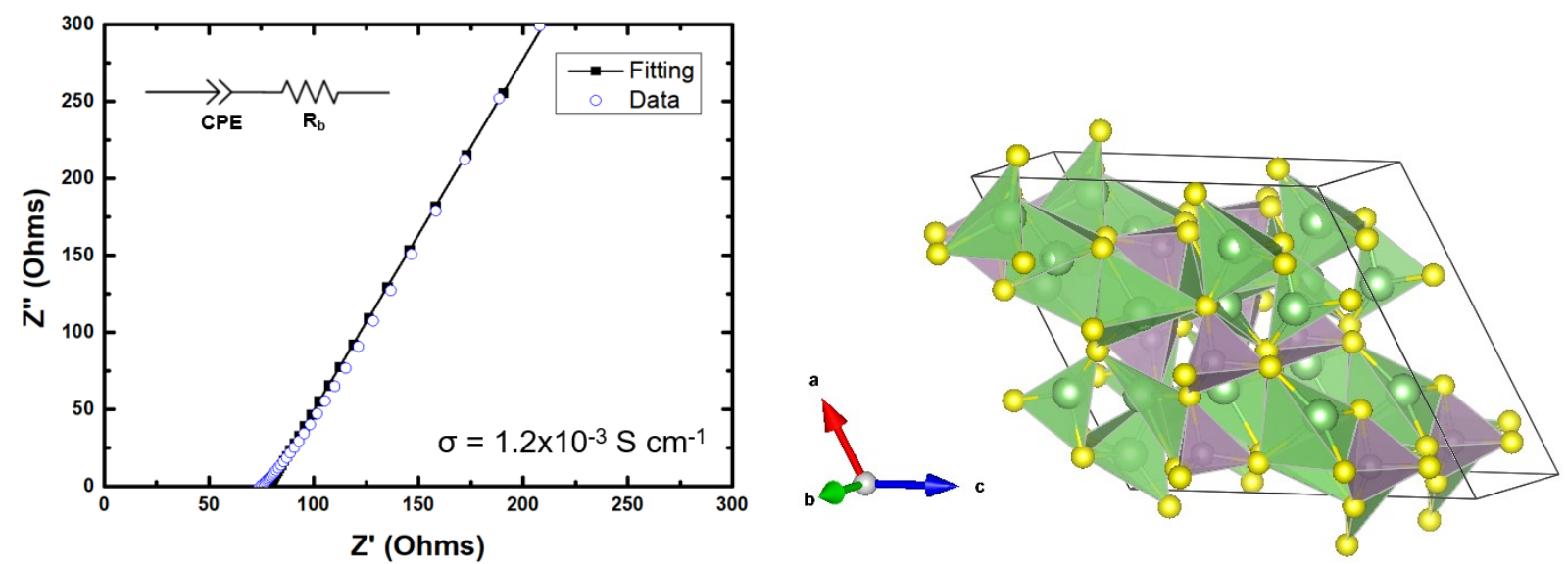

Fig. S1. Nyquist plot with fitting for synthesized $\mathrm{Li}_{7} \mathrm{P}_{3} \mathrm{~S}_{11}$. The ionic conductivity of $\mathrm{Li}_{7} \mathrm{P}_{3} \mathrm{~S}_{11}$ was measured at room temperature to be $1.2 \mathrm{mS} \mathrm{cm}^{-1}$. The characteristic single straight-line feature on the EIS diagram is representative of the bulk resistance component in the electrolyte, and capacitance at the blocking electrodes. SSE powders were first pelletized under $370 \mathrm{MPa}$ for 3 minutes before applying an $\mathrm{AC}$ potential of $30 \mathrm{mV}$ over a frequency range from $1 \mathrm{MHz}$ to $1 \mathrm{~Hz}$ in the EIS measurement. Crystal structure visualization of $\mathrm{Li}_{7} \mathrm{P}_{3} \mathrm{~S}_{11}$ is added for reference. 


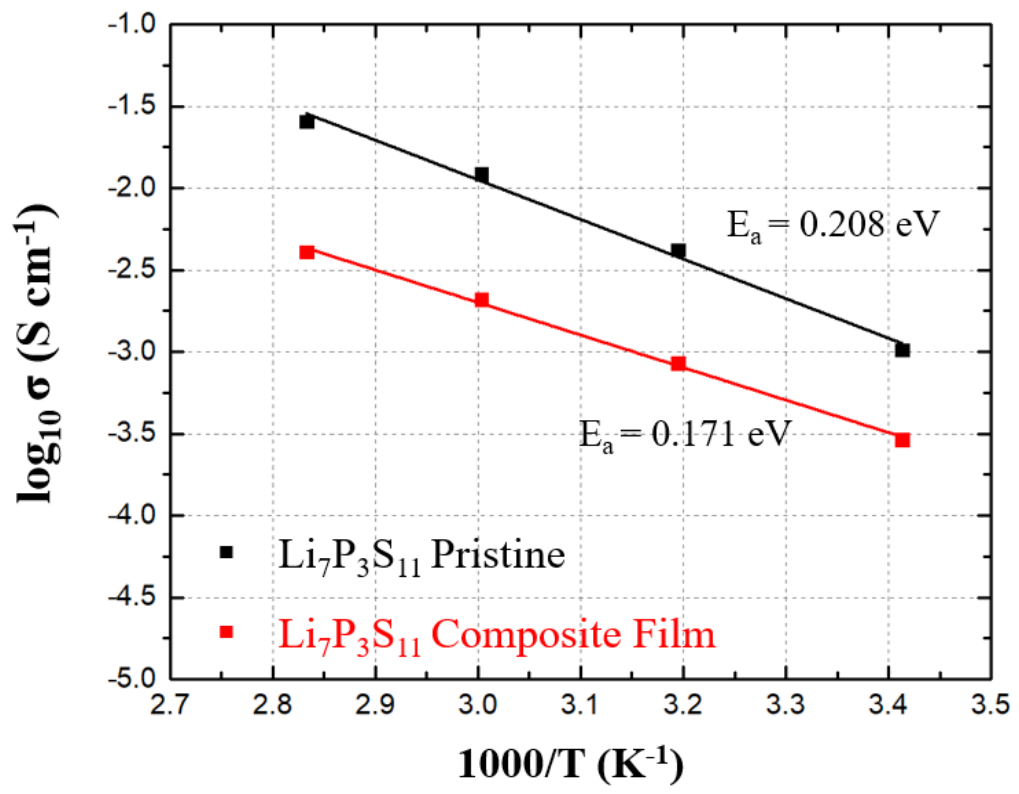

Fig. S2. Arrhenius Plot of the $95 \mathrm{wt} \% \mathrm{Li}_{7} \mathrm{P}_{3} \mathrm{~S}_{11}: 5 \mathrm{wt} \%$ SEBS electrolyte film. 

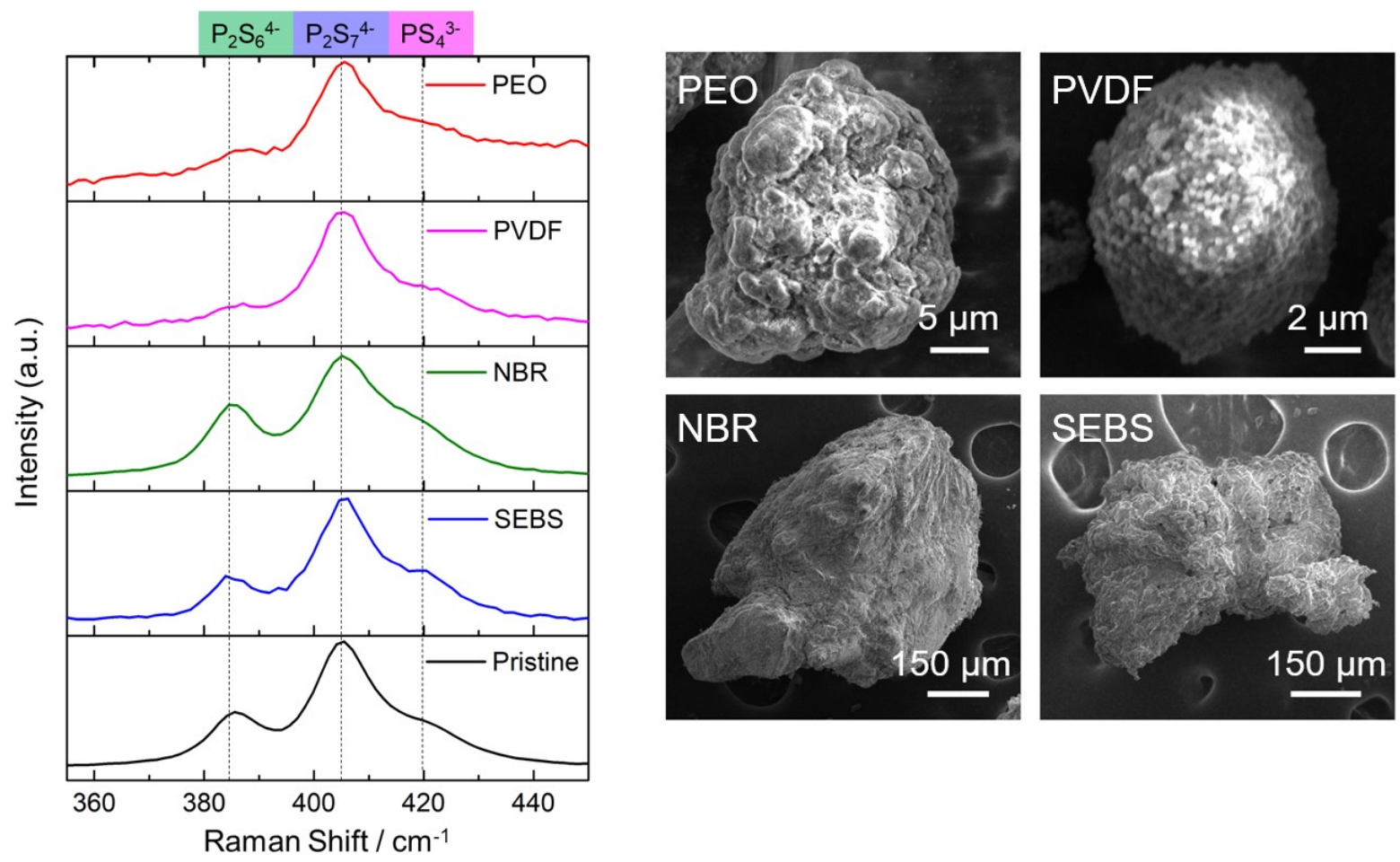

Fig. S3. Raman spectra of $\mathrm{Li}_{7} \mathrm{P}_{3} \mathrm{~S}_{11}$ - Polymer mixtures showing retention of both the peak positions and relative intensities of the lithium thiophosphate modes of $\mathrm{P}_{2} \mathrm{~S}_{7}{ }^{4-}$ at $406 \mathrm{~cm}^{-1}, \mathrm{PS}_{4}{ }^{3-}$ at $420 \mathrm{~cm}^{-1}$ and $\mathrm{P}_{2} \mathrm{~S}_{6}{ }^{4-}$ at $385 \mathrm{~cm}^{-1}$, indicating the retention of the local structures of $\mathrm{Li}_{7} \mathrm{P}_{3} \mathrm{~S}_{11}$ in the respective mixtures. Variations in the signal intensities across the mixtures were ascribed to signal interference due to the presence of the polymer, not to degradation in the respective vibration modes. The variations were more obvious in the PEO and PVDF mixtures as their powders were much finer than NBR and SEBS, which introduced more coverage over the SSE powders and interfered more strongly with the Raman signal. As a result, no chemical degradation of the electrolyte conduction modes was detected in each mixture through the Raman analysis. 

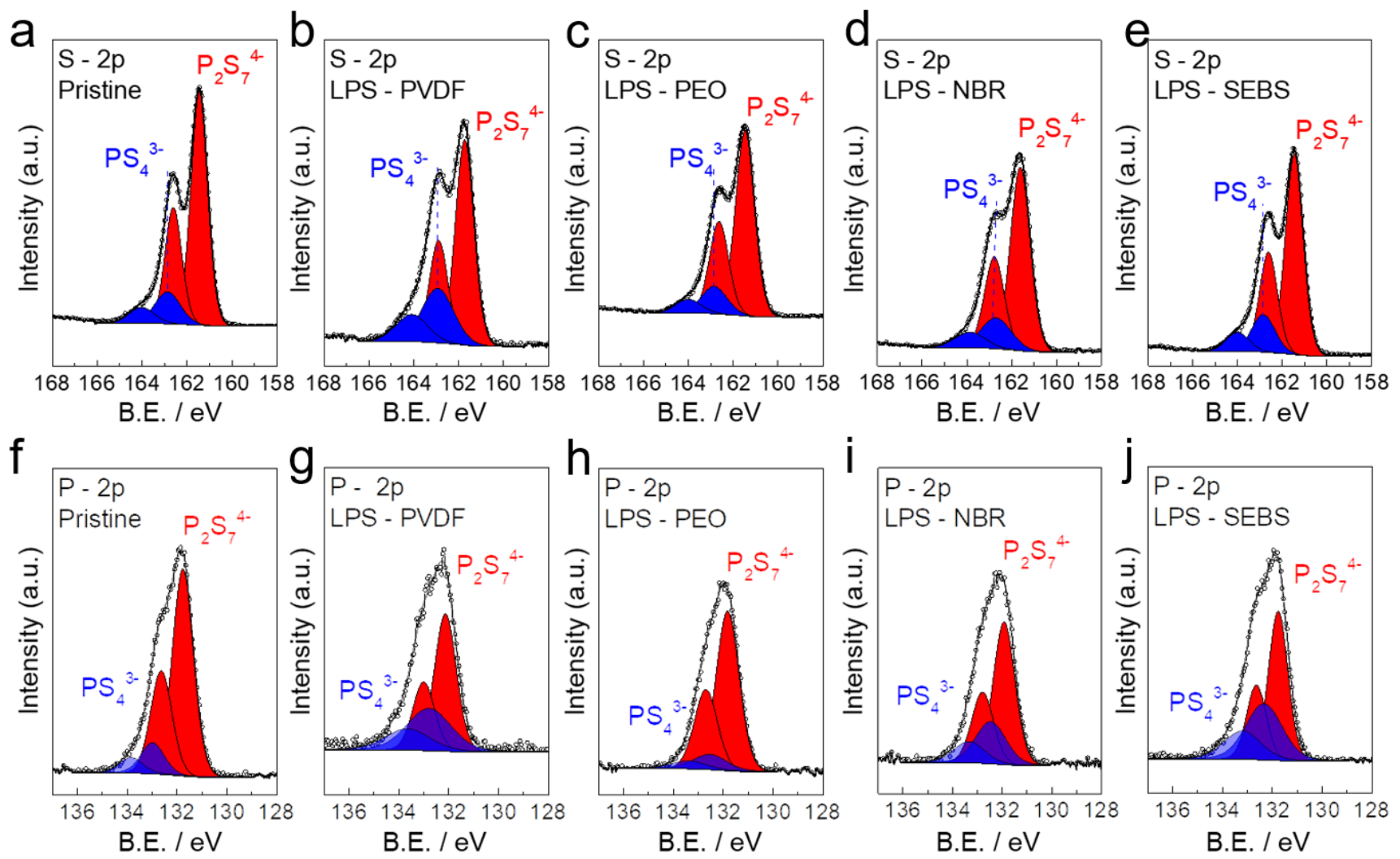

Fig. S4. XPS Binding energies of $\mathrm{Li}_{7} \mathrm{P}_{3} \mathrm{~S}_{11}$ - Polymer mixtures: (a) to (j) examines the binding energies of phosphorus and sulfur in the respective mixtures. No new reaction or decomposition products were detected by XPS. The characteristic peak patterns matched the pristine counterparts in both the phosphorous and sulfur regions, comprising the main components of $\mathrm{P}_{2} \mathrm{~S}_{7}{ }^{4-}$ and $\mathrm{PS}_{4}{ }^{3-}$. Small variations observed in the area under each deconvoluted curves were attributed to spot to spot inhomogeneities from the localized probes used in XPS, rather than changes in relative amounts of each local structure. From the above analyses, no chemical reactions or electrolyte decomposition from the dry mixtures of $\mathrm{Li}_{7} \mathrm{P}_{3} \mathrm{~S}_{11}$ and the respective polymers are detected. 

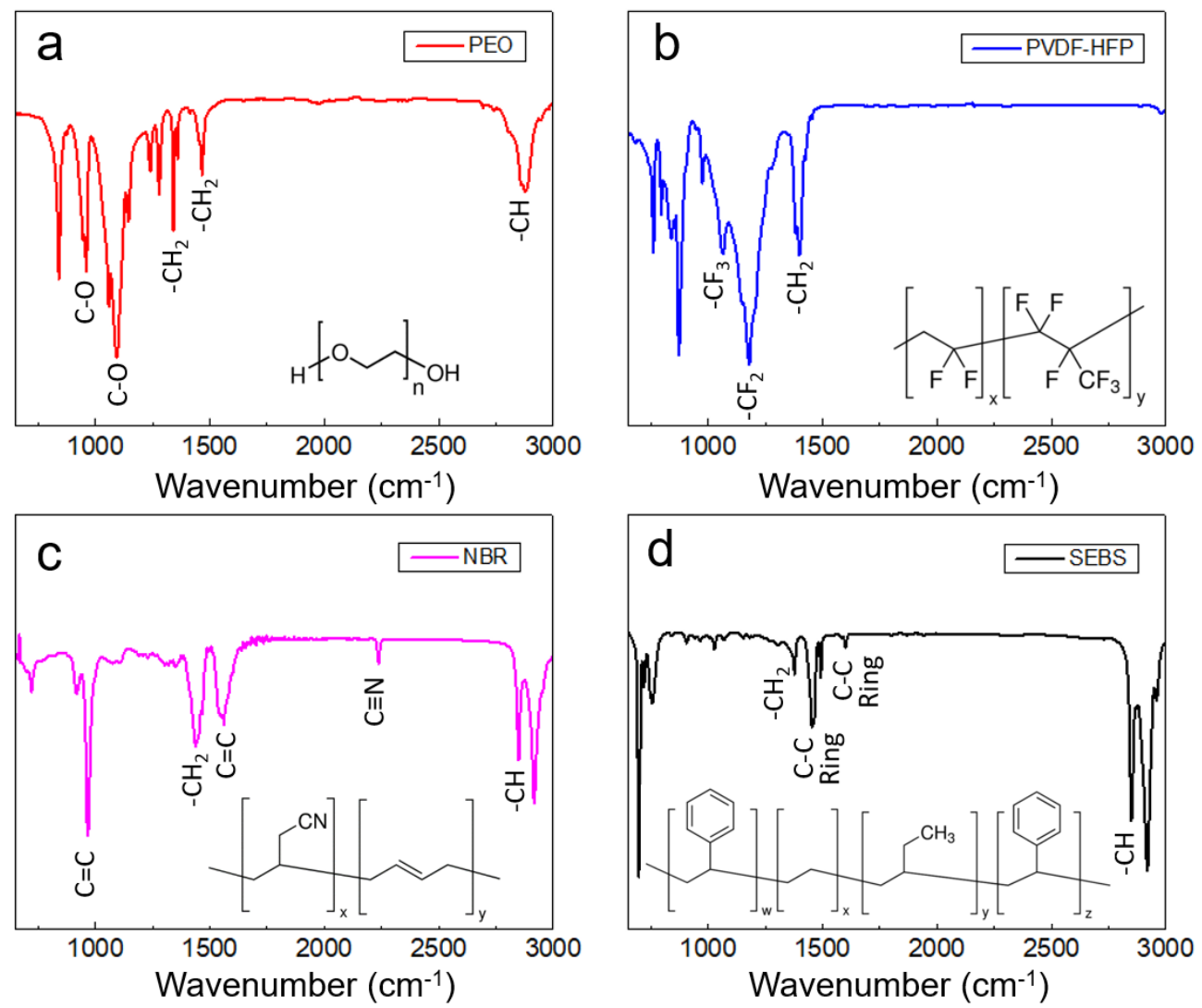

Fig. S5. FTIR spectrums of selected polymers. (a) PEO, (b) PVDF-HFP, (c) NBR, (d) SEBS. 


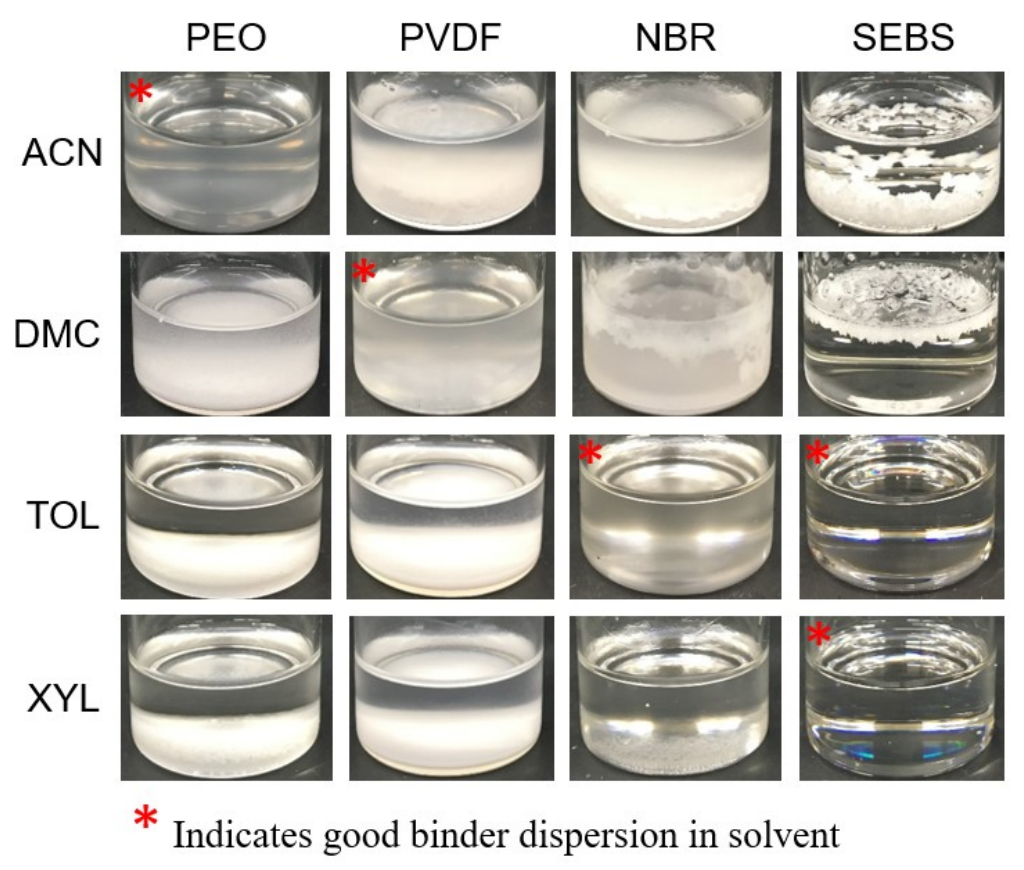

Fig. S6. PEO, PVDF, NBR, SEBS Polymer solutions in different solvents of ACN, DMC, Toluene and para-Xylene. 


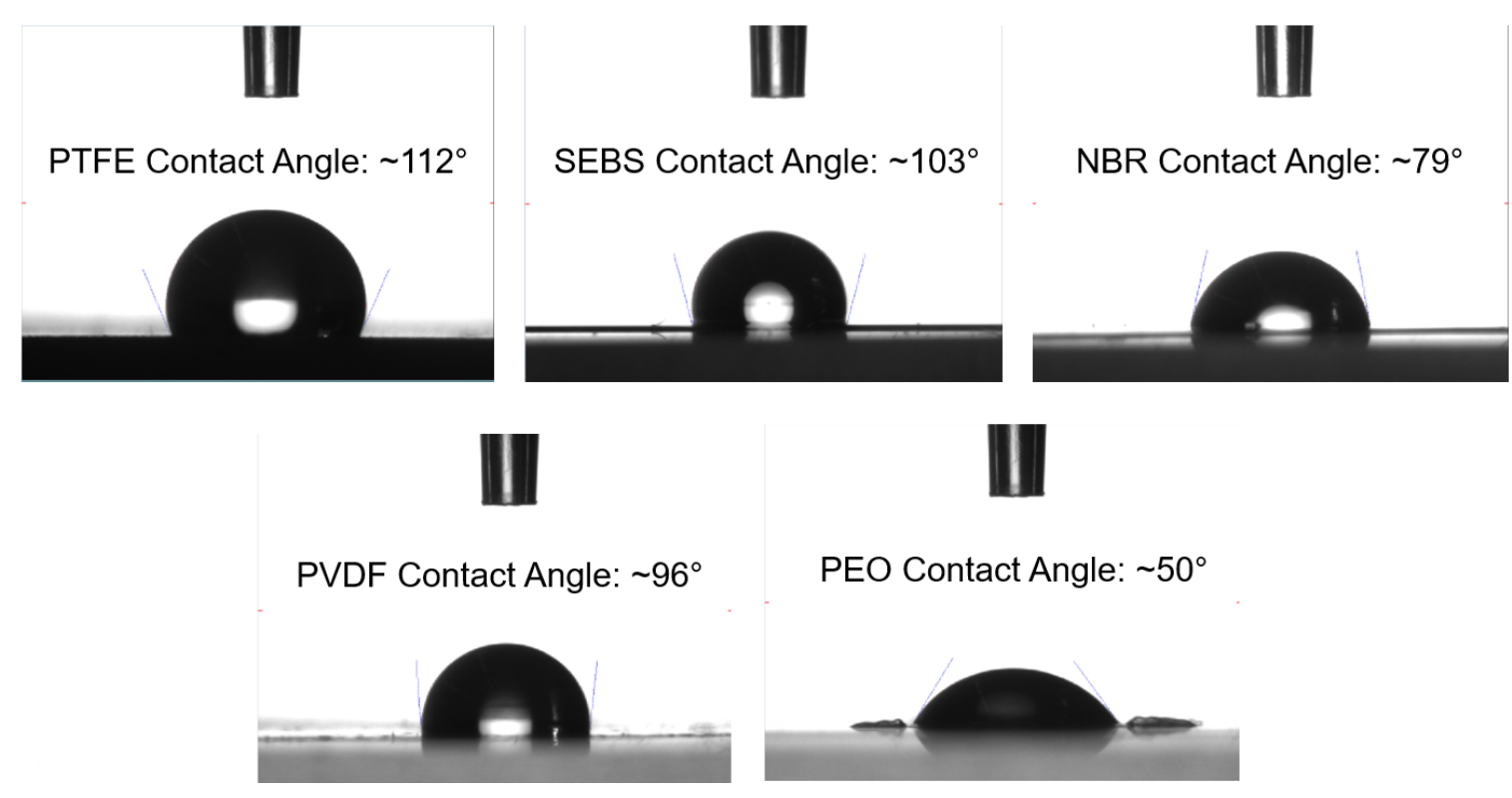

Fig. S7. SEBS, NBR, PVDF, PEO contact angles with water, indicating the hydrophobic natures of each polymer. PTFE is displayed for reference. 

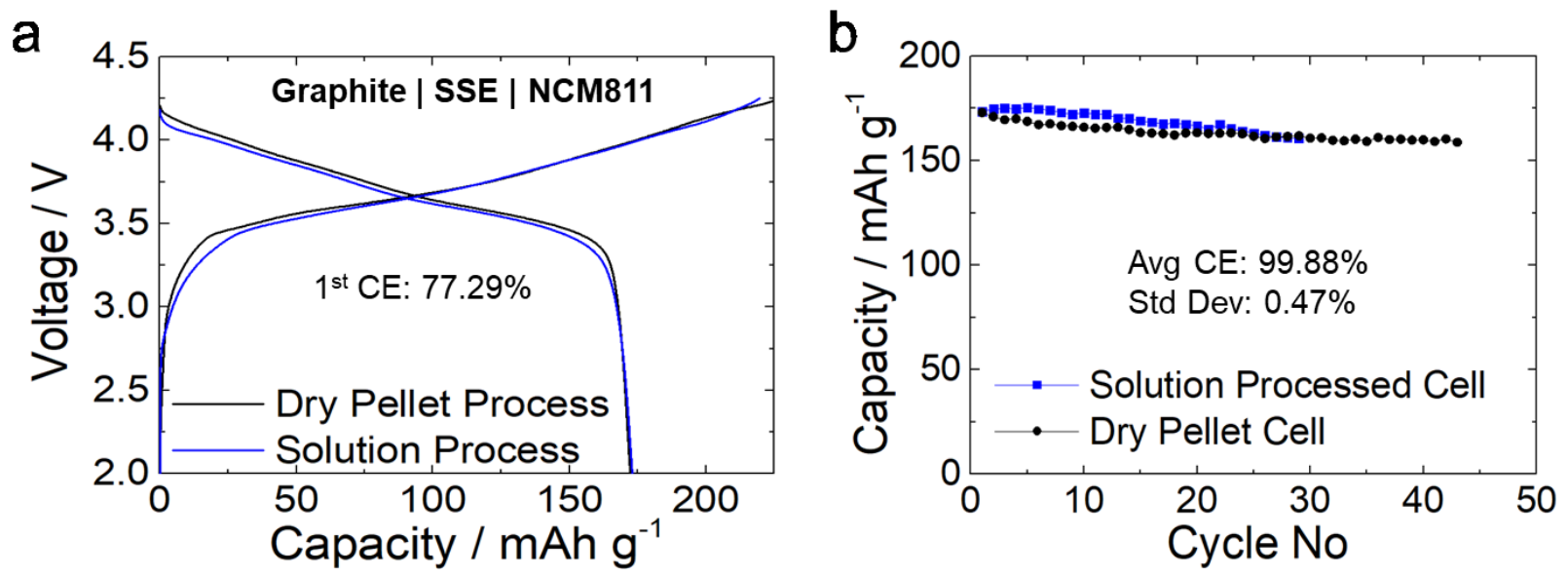

Fig. S8. a) The voltage profile of a full cell using Graphite | Thin SSE Composite Film | NCM811 compared to a dry pellet cell with a $\sim 700 \mu \mathrm{m}$-thick electrolyte, and b) a comparison of the cycling performance.

The full cell in Fig S8 was fabricated using the same solution process discussed in the manuscript, with the additional step of adding graphite / NCM811 for the anode / cathode slurries respectively. In a typical full cell, graphite and SSE in the weight ratio of $60: 40$ was dispersed in SEBS polymer dissolved XYL solvent, while NCM811, SSE and Carbon Black in the weight ratio of $66: 33: 1$ was dispersed in SEBS polymer dissolved XYL solvent. Each slurry was hand mixed in an agate mortar and pestle for 15 minutes before being casted with a doctor blade on copper current collector for the anode, and aluminum current collector for the cathode. The casted slurries were left to dry at room temperature for 1 hour and overnight at $60{ }^{\circ} \mathrm{C}$ under vacuum. The dried electrodes and electrolyte layers were cut pressed together under $370 \mathrm{MPa}$ of pressure for at least 3 minutes before cycling at room temperature under $0.1 \mathrm{C}$ between $2.00-4.25 \mathrm{~V}$. The typical active mass loading of NCM811 was determined to be $13 \mathrm{mg} \mathrm{cm}^{-2}$. The first cycle coulombic efficiency was found to be $77.29 \%$ with an average subsequent coulombic efficiency of $99.88 \%$ per cycle. 
Table S1. Summary of composite solid electrolytes reported in literature and their respective properties.

\begin{tabular}{|c|c|c|c|c|c|c|c|}
\hline $\begin{array}{c}\text { Solid Electrolyte } \\
\text { Type }\end{array}$ & Polymer & $\begin{array}{l}\text { SE I } \\
\text { wt } \%\end{array}$ & $\begin{array}{l}\text { Conductivity } \\
\qquad / \mathrm{S} \mathrm{cm}^{-1}\end{array}$ & $\begin{array}{l}\text { Temp } \\
I^{\circ} \mathrm{C}\end{array}$ & $\begin{array}{l}\text { Li Plating } \\
\quad / \mathrm{Hr}\end{array}$ & $\begin{array}{l}\text { Capacity I } \\
\text { mAh cm-2 }\end{array}$ & $\begin{array}{c}\text { Remarks } / \\
\text { Ref }\end{array}$ \\
\hline $\mathrm{Li}_{7} \mathrm{P}_{3} \mathrm{~S}_{11}$ & SEBS & 95 & $7 \times 10^{-4}$ & RT & 2000 & 1.1 & This work \\
\hline $\mathrm{Li}_{0.33} \mathrm{La}_{0.557} \mathrm{TiO}_{3}$ & PEO & 20 & $1.8 \times 10^{-4}$ & RT & 800 & 0.033 & 1 \\
\hline $\mathrm{Li}_{7} \mathrm{La}_{3} \mathrm{Zr}_{2} \mathrm{O}_{12}$ & PEO & 52.5 & $4.4 \times 10^{-4}$ & 55 & & - & 2 \\
\hline $\mathrm{Li}_{7} \mathrm{La}_{3} \mathrm{Zr}_{2} \mathrm{O}_{12}$ & PEO & 40 & $5 \times 10^{-5}$ & 80 & & - & 3 \\
\hline $\mathrm{Li}_{7} \mathrm{La}_{3} \mathrm{Zr}_{2} \mathrm{O}_{12}$ & PEO & 15 & $1.1 \times 10^{-4}$ & 40 & & - & 4 \\
\hline $\mathrm{Li}_{1.5} \mathrm{Al}_{0.5} \mathrm{Ge}_{1.5}\left(\mathrm{PO}_{4}\right)_{3}$ & PEO & 20 & $6.8 \times 10^{-4}$ & 60 & & - & 5 \\
\hline $\mathrm{Li}_{1.5} \mathrm{Al}_{0.5} \mathrm{Ge}_{1.5}\left(\mathrm{PO}_{4}\right)_{3}$ & PEO & 60 & $2.6 \times 10^{-4}$ & 55 & & - & 6 \\
\hline $\mathrm{Li}_{1.5} \mathrm{Al}_{0.5} \mathrm{Ge}_{1.5}\left(\mathrm{PO}_{4}\right)_{3}$ & PEO & 99 & $2 \times 10^{-5}$ & RT & & - & 7 \\
\hline $\mathrm{Li}_{1.3} \mathrm{Al}_{0.3} \mathrm{Ti}_{1.7}\left(\mathrm{PO}_{4}\right)_{3}$ & PEO & 50 & $1 \times 10^{-3}$ & 80 & 200 & 0.05 & 8 \\
\hline $\mathrm{Li}_{6.75} \mathrm{La}_{3} \mathrm{Zr}_{1.75} \mathrm{Ta}_{0.25} \mathrm{O}_{12}$ & PVDF & 10 & $5 \times 10^{-4}$ & 25 & & - & $9 *$ \\
\hline $\mathrm{Li}_{7} \mathrm{La}_{3} \mathrm{Zr}_{2} \mathrm{O}_{12}$ & PVDF & 50 & $1.1 \times 10^{-4}$ & $\mathrm{RT}$ & 420 & - & $10 *$ \\
\hline $\mathrm{Li}_{1.3} \mathrm{Al}_{0.3} \mathrm{Ti}_{1.7}\left(\mathrm{PO}_{4}\right)_{3}$ & PVDF & 66 & $9.6 \times 10^{-4}$ & RT & & - & $11 *$ \\
\hline $\mathrm{Li}_{1+x} \mathrm{Al}_{x} \mathrm{Ge}_{2-x}\left(\mathrm{PO}_{4}\right)_{3}$ & PVDF & 50 & $9.6 \times 10^{-4}$ & $\mathrm{RT}$ & 400 & - & $12 *$ \\
\hline $\mathrm{Li}_{1.3} \mathrm{Al}_{0.3} \mathrm{Ti}_{1.7}\left(\mathrm{PO}_{4}\right)_{3}$ & PVDF & 90 & $6.3 \times 10^{-4}$ & 30 & - & - & $13^{*}$ \\
\hline $\mathrm{Li}_{10} \mathrm{GeP}_{2} \mathrm{~S}_{12}$ & PEO & 1 & $1.2 \times 10^{-3}$ & 80 & & - & 14 \\
\hline $\mathrm{Li}_{3} \mathrm{PS}_{4}$ & NBR & 97.5 & $4.2 \times 10^{-4}$ & RT & & - & 15 \\
\hline $\mathrm{Li}_{3} \mathrm{PS}_{4}$ & SBS & 97 & $2 \times 10^{-4}$ & RT & & - & 16 \\
\hline $\mathrm{Li}_{6} \mathrm{PS}_{5} \mathrm{Cl}$ & NBR & 98.5 & - & 30 & & - & 17 \\
\hline $\mathrm{Li}_{6} \mathrm{PS}_{5} \mathrm{Cl}$ & PVP & 80 & $9.6 \times 10^{-6}$ & RT & & - & 18 \\
\hline
\end{tabular}


Table S2. Summary of selected polymers and solvents for the study and their illustrated molecular structures and abbreviations.

Polymer Structure Solvent


Supporting Information for Publication - Movie 1. Flexibility demonstration of synthesized electrolyte film enclosed in air sealed bag.

Supporting Information for Publication - Movie 2. Demonstration of adding water to: Bare Electrolyte and Composite Electrolyte with SEBS. 


\section{References}

1. Wang, X.; Zhang, Y.; Zhang, X.; Liu, T.; Lin, Y. H.; Li, L.; Shen, Y.; Nan, C. W., LithiumSalt-Rich $\mathrm{PEO} / \mathrm{Li}_{0.3} \mathrm{La}_{0.557} \mathrm{TiO}_{3}$ Interpenetrating Composite Electrolyte with Three-Dimensional Ceramic Nano-Backbone for All-Solid-State Lithium-Ion Batteries. ACS Appl. Mater. Interfaces 2018, 10 (29), 24791-24798.

2. Choi, J.-H.; Lee, C.-H.; Yu, J.-H.; Doh, C.-H.; Lee, S.-M., Enhancement of ionic conductivity of composite membranes for all-solid-state lithium rechargeable batteries incorporating tetragonal $\mathrm{Li}_{7} \mathrm{La}_{3} \mathrm{Zr}_{2} \mathrm{O}_{12}$ into a polyethylene oxide matrix. J. Power Sources 2015, 274, 458-463.

3. Langer, F.; Bardenhagen, I.; Glenneberg, J.; Kun, R., Microstructure and temperature dependent lithium ion transport of ceramic-polymer composite electrolyte for solid-state lithium ion batteries based on garnet-type $\mathrm{Li}_{7} \mathrm{La}_{3} \mathrm{Zr}_{2} \mathrm{O}_{12}$. Solid State Ionics 2016, 291, 8-13.

4. Tao, X.; Liu, Y.; Liu, W.; Zhou, G.; Zhao, J.; Lin, D.; Zu, C.; Sheng, O.; Zhang, W.; Lee, H. W.; Cui, Y., Solid-State Lithium-Sulfur Batteries Operated at 37 degrees $C$ with Composites of Nanostructured $\mathrm{Li}_{7} \mathrm{La}_{3} \mathrm{Zr}_{2} \mathrm{O}_{12} /$ Carbon Foam and Polymer. Nano Lett. 2017, 17 (5), 2967-2972.

5. Zhao, Y.; Huang, Z.; Chen, S.; Chen, B.; Yang, J.; Zhang, Q.; Ding, F.; Chen, Y.; Xu, X., A promising PEO/LAGP hybrid electrolyte prepared by a simple method for all-solid-state lithium batteries. Solid State Ionics 2016, 295, 65-71.

6. Jung, Y.-C.; Lee, S.-M.; Choi, J.-H.; Jang, S. S.; Kim, D.-W., All Solid-State Lithium Batteries Assembled with Hybrid Solid Electrolytes. J. Electrochem. Soc. 2015, 162 (4), A704A710.

7. Wang, C.; Yang, Y.; Liu, X.; Zhong, H.; Xu, H.; Xu, Z.; Shao, H.; Ding, F., Suppression of Lithium Dendrite Formation by Using LAGP-PEO (LiTFSI) Composite Solid Electrolyte and Lithium Metal Anode Modified by PEO (LiTFSI) in All-Solid-State Lithium Batteries. ACS Appl. Mater. Interfaces 2017, 9 (15), 13694-13702.

8. Ban, X.; Zhang, W.; Chen, N.; Sun, C., A High-Performance and Durable Poly(ethylene oxide)-Based Composite Solid Electrolyte for All Solid-State Lithium Battery. J. Phys. Chem. C 2018, 122 (18), 9852-9858.

9. Zhang, X.; Liu, T.; Zhang, S.; Huang, X.; Xu, B.; Lin, Y.; Xu, B.; Li, L.; Nan, C. W.; Shen, Y., Synergistic Coupling between $\mathrm{Li}_{6.75} \mathrm{La}_{3} \mathrm{Zr}_{1.75} \mathrm{Ta}_{0.25} \mathrm{O}_{12}$ and Poly(vinylidene fluoride) Induces High Ionic Conductivity, Mechanical Strength, and Thermal Stability of Solid Composite Electrolytes. J. Am. Chem. Soc. 2017, 139 (39), 13779-13785.

10. Zhang, W.; Nie, J.; Li, F.; Wang, Z. L.; Sun, C., A durable and safe solid-state lithium battery with a hybrid electrolyte membrane. Nano Energy 2018, 45, 413-419.

11. Shi, X.; Ma, N.; Wu, Y.; Lu, Y.; Xiao, Q.; Li, Z.; Lei, G., Fabrication and electrochemical properties of LATP/PVDF composite electrolytes for rechargeable lithium-ion battery. Solid State Ionics 2018, 325, 112-119.

12. Guo, Q.; Han, Y.; Wang, H.; Xiong, S.; Li, Y.; Liu, S.; Xie, K., New Class of LAGP-Based Solid Polymer Composite Electrolyte for Efficient and Safe Solid-State Lithium Batteries. ACS Appl. Mater. Interfaces 2017, 9 (48), 41837-41844.

13. Liang, X.; Han, D.; Wang, Y.; Lan, L.; Mao, J., Preparation and performance study of a PVDF-LATP ceramic composite polymer electrolyte membrane for solid-state batteries. RSC Adv. 2018, 8 (71), 40498-40504.

14. Zhao, Y.; Wu, C.; Peng, G.; Chen, X.; Yao, X.; Bai, Y.; Wu, F.; Chen, S.; Xu, X., A new solid polymer electrolyte incorporating $\mathrm{Li}_{10} \mathrm{GeP}_{2} \mathrm{~S}_{12}$ into a polyethylene oxide matrix for all-solidstate lithium batteries. J. Power Sources 2016, 301, 47-53. 
15. Lee, K.; Kim, S.; Park, J.; Park, S. H.; Coskun, A.; Jung, D. S.; Cho, W.; Choi, J. W., Selection of Binder and Solvent for Solution-Processed All-Solid-State Battery. J. Electrochem. Soc. 2017, 164 (9), A2075-A2081.

16. Sakuda, A.; Kuratani, K.; Yamamoto, M.; Takahashi, M.; Takeuchi, T.; Kobayashi, H., All-Solid-State Battery Electrode Sheets Prepared by a Slurry Coating Process. J. Electrochem. Soc. 2017, 164 (12), A2474-A2478.

17. Nam, Y. J.; Oh, D. Y.; Jung, S. H.; Jung, Y. S., Toward practical all-solid-state lithium-ion batteries with high energy density and safety: Comparative study for electrodes fabricated by dryand slurry-mixing processes. J. Power Sources 2018, 375, 93-101.

18. Shao, C.; Liu, H.; Yu, Z.; Zheng, Z.; Sun, N.; Diao, C., Structure and ionic conductivity of cubic $\mathrm{Li}_{7} \mathrm{La}_{3} \mathrm{Zr}_{2} \mathrm{O}_{12}$ solid electrolyte prepared by chemical co-precipitation method. Solid State Ionics 2016, 287, 13-16. 